\title{
HIV medicine
}

\section{HIV infection and seizures}

\author{
Ravindra Kumar Garg
}

\section{Summary}

New-onset seizures are frequent manifestations of central nervous system disorders in patients infected with human immunodeficiency virus (HIV). Seizures are more common in advanced stages of the disease, although they may occur early in the course of illness. In the majority of patients, seizures are of the generalised type. Status epilepticus is also frequent. Associated metabolic abnormalities increase the risk for status epilepticus. Cerebral mass lesions, cryptococcal meningitis, and HIV-encephalopathy are common causes of seizures. Phenytoin is the most commonly prescribed anticonvulsant in this situation, although several patients may experience hypersensitivity reactions. The prognosis of seizure disorders in HIV-infected patients depends upon the underlying cause.

Keywords: AIDS; human immunodeficiency virus; seizures; epilepsy; toxoplasmosis

Department of Neurology, Institute of Medical Sciences, Banaras Hindu University, Varanasi, 221005 India R K Garg

Accepted 16 March 1999
Disorders of the central nervous system (CNS) in patients with human immunodeficiency virus (HIV) type-1 infection is often associated with severe morbidity and mortality. Seizures are relatively common manifestations of HIV infection itself and of its several complications involving the brain. ${ }^{1-6}$

\section{Incidence}

Available data on the incidence of new-onset seizures in HIV-infected persons are derived from hospital-based studies. Wong $e t a l^{\beta}$ observed an incidence of $11 \%$ among $630 \mathrm{HIV}$-infected patients. In a more recent study, Van Paesschen et $a l^{4}$ observed that $4 \%$ of AIDS patients had new-onset seizures. In their study, the incidence of seizures was much lower than in the former study, presumably because strict inclusion criteria were applied. All patients were admitted, or were already in-patients, on the day of first seizure. Out of 68 selected patients, 62 had acquired immunodeficiency syndrome (AIDS), only six (9\%) patients had AIDS-related complex or were asymptomatic HIV-seropositive. ${ }^{4}$ In the study by Wong et $a l^{3}{ }^{3} 28 \%$ of the patients had AIDS-related complex or were asymptomatic HIV-seropositive.

\section{Associated seizure disorders}

In most AIDS patients, seizures are seen in advanced stages of the disease. ${ }^{34}$ Dore $e t a l$ in a case-control study observed that $84 \%$ of such patients had prior AIDS-defining illness, and mean CD4 T-cell count was $8 \times 10^{6}$ cells $/ \mu \mathrm{l}$, while in a control group (patients without seizures) mean CD4 T-cell count was $14 \times 10^{6}$ cells $/ \mu 1$, and AIDS-defining illness was present in $80 \%$ of the patients.

Seizures may be the presenting clinical symptom of HIV disease. In a few patients seizures can occur early in the course of HIV-infection. The majority of patients have generalised seizures; partial seizures are less frequently observed and do not necessarily imply the presence of focal mass lesions. ${ }^{1-6}$ Both simple and complex partial seizures are seen in patients with diffuse brain disease, such as HIV encephalopathy and meningitis. ${ }^{3}$ The incidence of convulsive status epilepticus has been reported as between $8 \%$ and $18 \%$ in different studies, ${ }^{2-4}$ and is often associated with poor prognosis. The frequent occurrence of generalised seizures and status epilepticus suggests that the HIV-infected brain has a low cortical excitability and impaired mechanisms for terminating seizure activity. Electroencephalographic (EEG) findings are usually non-specific, diffuse slowing being the most common abnormality. Focal slowing and epileptiform activities are infrequently seen. ${ }^{23}$

\section{Aetiology}

Work-up for HIV-infected patients presenting with new-onset seizures includes neuroimaging studies (computed tomography (CT), magnetic resonance imaging (MRI), and cerebrospinal fluid (CSF) analysis), as well as blood chemistry and, in some patients, neuropathological studies of biopsied brain tissue. In a few patients, diagnosis may not be clear until post-mortem neuropathological evaluation. Approximately $50-60 \%$ of patients have an apparent secondary disease process to which the seizures can be attributed; at rest, no demonstrable cause is seen (table). ${ }^{1-7}$ Various electrolyte and metabolic disturbances, such as hyponatraemia, hypomagnesaemia and renal failure, are associated with an increased risk of seizure recurrence and increased occurrence of convulsive status epilepticus. $^{2}{ }^{4}$

\section{Mass lesions}

Intracranial mass lesions account for nearly half the neurological disorders in AIDS patients. The nature of these mass lesions can be broadly divided into 
Table Causes of seizures in HIV infected patients : a summary of observations of 4 studies

\begin{tabular}{|c|c|c|c|}
\hline Holtzman et al ${ }^{2}(n=100)$ & Wong et al $(n=70)$ & Van Paesschen et al $(n=68)$ & Dore et $a l^{5}(n=50)$ \\
\hline $\begin{array}{l}\text { Mass lesions : } \mathbf{3 2} \\
\text { toxoplasmosis - } 28 \\
\text { lymphoma - } 6 \\
\text { HIV-encephalopathy:24 } \\
\text { Meningitis : } \mathbf{1 6} \\
\text { cryptococcal - } 13 \\
\text { herpes zoster - } 1 \\
\text { aseptic - } 1 \\
\text { toxoplasmosis - } 1 \\
\text { Others : } 8 \\
\text { hyponatraemia - } 2 \\
\text { stroke - } 3 \\
\text { TTP - } 1 \\
\text { PML - } 1 \\
\text { renal failure - } 1 \\
\text { Non-identifiable : } 23\end{array}$ & $\begin{array}{l}\text { toxoplasmosis - } 11 \\
\text { lymphoma - } 8 \\
\text { metabolic - } 8 \\
\text { cryptococcal meningitis - } 7 \\
\text { vascular infarction - } 4 \\
\text { non-identifiable (HIV-encephalopathy) - } 32\end{array}$ & $\begin{array}{l}\text { Mass lesions : } \mathbf{2 5} \\
\text { toxoplasmosis - } 8 \\
\text { other cerebral mass lesions - } 11 \\
\text { non-identified - } 6 \\
\text { Meningoencephalitis: } \mathbf{8} \\
\text { cryptococcal - } 3 \\
\text { herpeszoster - } 1 \\
\text { neurosyphilis - } 1 \\
\text { toxoplasma - } 1 \\
\text { tuberculous - } 1 \\
\text { unclear - } 1 \\
\text { Stroke - 3 } \\
\text { Drug abusers - 2 } \\
\text { With cerebral atrophy (? HIV-dementia ) - } \mathbf{2 8} \\
\text { Non-identified - } \mathbf{3}\end{array}$ & $\begin{array}{l}\text { toxoplasmosis - } 11 \\
\text { cryptococcal meningitis - } 4 \\
\text { PML - } 3 \\
\text { CMV encephalitis - } 3 \\
\text { lymphoma - } 1 \\
\text { other causes (pre-HIV) seizures - } 7 \\
\text { non-identifiable cause - } 21\end{array}$ \\
\hline
\end{tabular}

HIV: human immunodeficiency virus, TTP: thrombotic thrombocytopenic purpura; PML: progressive multifocal leukoencephalopathy; CMV: cytomegalovirus.

\author{
Focal CNS lesions associated \\ with seizures in HIV-infected \\ patients \\ Infections \\ - toxoplasmosis \\ - cryptococcal granuloma \\ - tuberculoma \& tuberculous abscess \\ - cysticercus granuloma \\ - Herpes zoster \\ - neurosyphilis \\ - nocardial abscesses \\ Neoplasm \\ - primary CNS lymphoma \\ Demyelination \\ - progressive multifocal \\ leukoencephalopathy \\ Cerebrovascular diseases \\ - cerebral infarction \\ - intracerebral haemorrhage
}

Box 1 three distinct groups: opportunistic infections, neoplasms, and cerebrovascular diseases. Seizures are dominant manifestations of most of these disorders (box 1). ${ }^{8}$

Toxoplasmosis is the most common cause of intracranial mass lesions in AIDS and occurs in $3-10 \%$ of patients in the USA and in up to $50 \%$ of patients in Europe and Africa. ${ }^{8}$ Seizures have been reported as an early manifestation in $15-40 \%$ of patients with cerebral toxoplasmosis. ${ }^{19}$ The diagnosis is usually made by demonstrating the presence of ring-enhancing lesions on CT scan, positive toxoplasma antibody titre, and clinical improvement with antitoxoplasma treatment which is confirmed by repeat CT brain scan. ${ }^{10}$ Various studies have described different incidences (12-28\%) of toxoplasmosis in patients with newonset seizures among HIV infected persons. ${ }^{245}$ Identification of cerebral toxoplasmosis is important because timely treatment with sulfadiazine and pyrimethamine is most likely to result in rapid clinical improvement.

Primary CNS lymphoma, the second most common cause of AIDS-related intracranial mass lesions, occurs in up to $2 \%$ of patients with AIDS. ${ }^{8}$ It is also the second most common mass lesion producing seizures in HIV-infected persons. A number of imaging features are helpful in distinguishing this condition from cerebral toxoplasmosis. Involvement of, and extension across, the corpus callosum is frequent in primary CNS lymphoma. Exclusive involvements of white matter, periventricular location and sub-ependymal spread (seen as contrast enhancement along the ventricular surface) are also common in lymphoma. ${ }^{10}$

Other causes of intracranial mass lesions which are likely to produce seizures in AIDS patients include tuberculous abscesses ${ }^{11}$ and tuberculomas, ${ }^{12}$ cryptococcal abscesses, ${ }^{10}$ nocardial abscesses, ${ }^{13}$ syphilitic gummas and cerebrovascular diseases when accompanied by oedema. ${ }^{14}$

\section{Other focal lesions}

Other focal lesions without significant mass effect, such as progressive multifocal leukoencephalopathy (PML) may also be responsible for new-onset seizures in several AIDS patients (figure). Moulignier et $a l^{15}$ reported on $10 \mathrm{HIV}$-infected patients with PML in whom partial or generalised seizures were the presenting neurological manifestations. They suggested that demyelinated lesions adjacent to the cerebral cortex acting as irritative foci, axonal conduction abnormalities, or disturbance of the neuron-glia balance are the possible reasons for a pure white matter disease producing seizures. Confirmation of the diagnosis of PML requires neuropathological studies of biopsied brain tissue from the lesion (box 2).

\section{Meningitis and encephalitis}

In patients without mass lesions, meningo-encephalitis caused by some opportunistic infections is a frequent source of seizures. The incidence of meningitis and encephalitis in HIV-infected patients with new onset seizures varies from $12 \%$ to $16 \%$. Cryptococcal meningitis is the most frequent meningoencephalitis producing seizures..$^{2-6}$ To confirm the diagnosis, an India ink preparation of CSF should be examined for cryptococcal antigen; fungal culture may increase the diagnostic yield. 


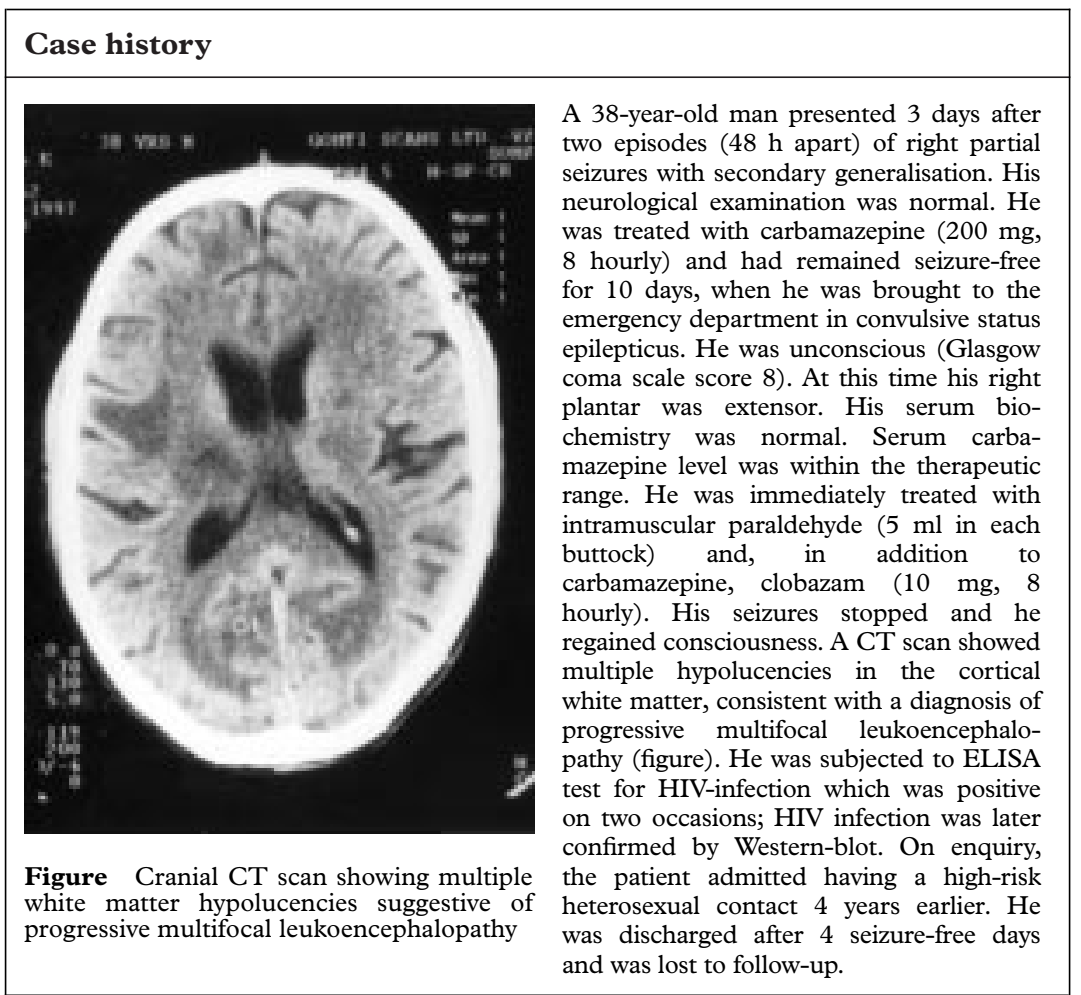

Box 2

Infrequent causes include aseptic meningitis, neurosyphilis, Herpes zoster leukoencephalitis, toxoplasma and cytomegalovirus encephalitis. ${ }^{5}$ In the developed countries, subacute sclerosing panencephalitis has re-emerged in children infected with HIV and can present with seizures and encephalopathy. The diagnosis is confirmed with characteristic periodic electroencephalographic changes and high measles antibody titre in CSF. ${ }^{16}$

\section{HIV infection}

Approximately half of HIV-infected patients with seizures have no definite identifiable disease of the brain, and cerebral HIV infection seems to be the most likely cause of the seizures. ${ }^{1-7}$ Navia et $a l^{17}$ reported nine patients with AIDS-dementia complex who had new-onset seizures and in whom autopsies did not reveal any secondary infections or neoplastic processes. The authors considered direct HIV infection of brain to be the cause of the seizures. In the study by Holtzman et al, ${ }^{2} \mathrm{HIV}$ encephalopathy was responsible for seizures in $24 \%$ of the patients. The diagnosis was established with the help of characteristic clinical features and histopathology of brain tissues. Later, in a series by Wong et $a l^{3}{ }^{3} 17$ patients within an unidentified group underwent post-mortem neuropathological examination of brain; six of them had microglial nodules or multinucleated cells or both, suggesting the diagnosis of HIV infection as a primary cause of seizures. In a series by Van Paesschen et $a l,{ }^{4} 41 \%$ of patients had cerebral atrophy on CT scan without meningitis or other demonstrable CT lesions. Autopsies of two patients from the latter group who died after seizure onset revealed subacute HIV-associated encephalitis in one patient, and cytomegalovirus encephalitis in the other. In a more recent study, Dore et $a \bar{l}$ observed that $42 \%$ of cases had no identifiable cause of seizures, although $18 \%$ of patients were receiving foscarnet therapy. They suggested that foscarnet therapy and subclinical HIV-1 involvement of the brain may be factors responsible for seizure activity. Thus, available data strongly suggest an epileptogenic role of HIV infection of the brain.

Among the various pathologies reported in the brain of patients of AIDS is neuronal injury and loss, however, neurons themselves are not infected by HIV. There is strong evidence for the existence of HIV- or immune-related toxins that produce injury or death of neurons via a potentially complex interaction between macrophages, microglia, or monocytes, especially after interacting with astrocytes. These neurotoxic substances can lead to increased glutamate release 


\section{Summary points}

- seizures are common manifestations of CNS involvement in HIV-infected patients

- generalised seizures are the most common type of seizures encountered

- convulsive status epilepticus is also common because of frequent serum electrolyte abnormalities

- lumbar puncture, CT, and MRI, if available, along with assessment of serum biochemical parameters are needed for evaluation

- cerebral mass lesions (eg, toxoplasmosis), HIV-encephalopathy, and cryptococcal meningitis, are the commonest causes of seizures in these patients

- phenytoin is the most widely prescribed anti-epileptic drug; hypersensitivity reactions are common

- prognosis depends upon the underlying cause

Box 4

or decreased glutamate re-uptake. This mechanism involves the activation of voltage-dependent calcium channels and $N$-methyl-D-aspartate (NMDA) receptor-operated channels and influx of calcium inside the neurons and other cells. The same mechanisms which have been proposed for the pathogenesis of the AIDS-dementia complex are considered responsible for early and late occurrences of seizures in these patients (box 3). ${ }^{18}$

\section{Drugs}

HIV-related seizures may also be provoked by concurrently administered drugs, for example, foscarnet therapy. ${ }^{20}$ Solomon et $a l^{21}$ reported one HIV-infected patient who developed new-onset generalised seizures following a single topical application of lindane for scabies.

\section{Treatment}

Seizure recurrences are frequent among these patients. Long-term anti-epileptic therapy needs to be considered, even after a single seizure. Phenytoin has been the most widely prescribed anti-epileptic drug for these patients, but a significant number of patients are likely to experience undesirable side-effects, including skin rashes, leucopenia, thrombocytopenia and hepatic dysfunction. Phenobarbitone and valproate are satisfactory alternatives in this situation. ${ }^{23}{ }^{19}$ Patients with mass lesions may experience seizure recurrence despite adequate plasma concentrations of anti-epileptic drug. ${ }^{3}$ As patients with HIV disease are likely to take long-term anti-epileptic medication, this may lead to drug interactions as a result of hepatic enzyme induction. Anti-epileptic drugs may also reduce the plasma concentrations of the protease inhibitors and so reduce their antiviral efficacy. ${ }^{22}$

\section{Conclusion}

Seizures are frequently associated with neurological manifestations of HIV infection. Correct diagnosis of underlying causes and their treatment along with anticonvulsant therapy is required for proper management. Proper control of seizures will help to improve the quality of life in these patients who are already suffering from a dreaded disease.

10 Provenzale JM, Jinkins JR. Brain and spine imaging findings in AIDS patients. Radiol Clin North Am 1997;35:1127-66.

1 Aronow HA, Feraru ER, Lipton RB. New-onset seizures in AIDS patients: etiology, prognosis, and treatment. Neurology 1989;39 (supp 1):428.

2 Holtzman DM, Kaku DA, So YT. New-onse seizures associated with human immunodeficiency virus infection: causation and clinica features in 100 cases. Am $\mathcal{F}$ Med 1989;87:173-7.

3 Wong MC, Suite NDA, Labar DR. Seizures in human immunodeficiency virus infection. Arch Neurol 1990;47:640-2.

4 Van Paesschen W, Bodian C, Maker H. Metabolic abnormalities and new- onset seizures in human immunodeficiency virus - seropositive patients. Epilepsia 1995;36:146-50.

5 Dore GJ, Law MG, Brew BJ. Prospective analysis of seizures occurring in human immunodeficiency virus type-1 infection. $\mathcal{F}$ Neuro AIDS 1996;1:59-69.

6 Labar DR. Seizures and HIV infection. In: Ped-

ley TA, Meldrum BS, eds. Recent advances in ley TA, Meldrum BS, eds. Recent advances in
epilepsy. Edinburgh: Churchill Livingstone, epilepsy. Edinburgh $119-26$.

7 Rosenbaum GS, Klein NC, Cunba BA. Early seizures in patients with acquired immunodeficiency syndrome without mass lesion. Hear Lung 1989;18:526-9.

8 Report of the Quality Standards Subcommittee of the American Academy of Neurology. Evaluation and management of intracranial mas lesions in AIDS. Neurology 1998;50:21-6.

9 Wong MC, Suite NDA, Labar DR. Seizures and HIV infection. Neurology 1989;39(suppl):362.
11 Farrar DJ, Flanigan TP, Gordon NM, Gold RL, Rich JD. Tuberculous brain abscess in a patient Rich JD. Tuberculous brain abscess in a patient with HIV infection: case

12 Martinez-Vazquez C, Bordon J, RodriguezGonzalez A, et al. Cerebral tuberculoma - a comparative study in patients with or without HIV infection. Infection 1995;23:49-53.

13 Mamelak AN, Obana WG, Flaherty JF, Rosenblum ML. Nocardial brain abscess: treatment strategies and factors influencing the outcome. Neurosurgery 1994;35:622-31.

14 Moriarty DM, Haller JO, Loh JP, Fikrig S. Cerebral infarction in pediatric acquired immunodeficiency syndrome. Pediatr Radiol 1994:24: 611-2.

15 Moulignier A, Mikol J, Pialoux G, Fenelon G, Gray F, Thiebaut JB. AIDS-associated progressive multifocal leukoencephalopathy revealed by sive multifocal leukoencephalopathy revealed new-onset seizures. Am fMed 1995;99:64-8.
Koppel BS, Poon TP, Khandji A, Pavlakis SG

16 Koppel BS, Poon TP, Khandji A, Pavlakis SG, and magnetic resonance imaging. I Neuroimaging 1996;6:22-5.

17 Navia B, Jordan B, Price R. The AIDSdementia complex: I Clinical features. Ann Neurol 1986;19:517-24.

18 Lipton SA. AIDS-related dementia and calcium homeostasis. Ann NY Acad Sci 1994;747:20524
19 Delanty N, Vaughan CJ, French JA. Medical causes of seizures. Lancet 1998;352:383-90.

20 Lor E, Liu YQ. Neurological sequelae associated with foscarnet therapy. Ann Pharmacother 1994;28:1035-7.

21 Solomon BA, Haut SR, Carr EM, Shlita AR. Neurotoxic reaction to lindane in an HIVseropositive patient. An old medication's new problem. F Fam Pract 1995;40:291-6.

22 Barry M, Gibbons S, Back D, Mulcahy F. Protease inhibitors in patients with HIV disease. Clinically important pharmacokinetic considerations. Clin Pharmacokinet 1997;32:194-209. 